\title{
Prevalence of ischaemic heart disease: the Caerphilly and Speedwell surveys
}

\author{
D BAINTON, * I A BAKER, P M SWEETNAM, J W G YARNELL, P C ELWOOD \\ From Bristol and Weston Health Authority, Bristol; and the Medical Research Council Epidemiology Unit, \\ Cardiff
}

SUMMARY Mortality from ischaemic heart disease remains high in the United Kingdom, and the present report describes the prevalence of the various epidemiological manifestations of the disease in two recent community studies with a common core protocol, each containing samples of over 2000 men, carried out in South Wales (Caerphilly) and the West of England (Speedwell, Bristol). The prevalence of electrocardiographic evidence of ischaemia was similar in the two communities $-8.7 \%$ of men aged $45-49$ years rising to $18.6 \%$ in men aged $55-59$ years in the samples from South Wales, and $8.0 \%$ and $17.2 \%$ respectively in the Bristol population. The overall prevalence of angina was 7.7\% in Caerphilly and 7.8\% in Speedwell in men aged 45-59 years, but symptoms of severe chest pain were more commonly reported in South Wales than in Speedwell $(10 \cdot 1 \%$ compared with $6 \cdot 3 \%)$. The data, however, suggested that the overall prevalence of ischaemic heart disease was very similar in the two areas. The prevalence of ischaemic heart disease was compared with that found in other population studies carried out in the United Kingdom and was higher than that found when employed men only were studied. There were substantial differences in mortality between the two areas; possible reasons for this are differences in community or medical services, smoking habit, or unemployment rates.

Any recent decline in mortality from ischaemic heart disease in the United Kingdom has been modest compared with that experienced by the United States and some other western countries. ${ }^{1}$ A few British studies carried out between 1968 and 1980 have described the prevalence of ischaemic heart disease in working populations $\mathrm{s}^{3}$ and in the general population. ${ }^{4}$ We describe the prevalence of the various manifestations of ischaemic heart diseasehistory of possible myocardial infarction, angina, and electrocardiographic evidence of ischaemia-in two recent community studies with a common core protocol. These prevalence figures were compared with those found in the other British studies.

Requests for reprints to Dr P C Elwood, MRC Epidemiology Unit, 4 Richmond Road, Cardiff CF2 3AS.

^Present address: Huddersfield Health Authority, St Luke's House, Blackmoorfoot Road, Huddersfield HD4 5RH.

Accepted for publication 27 July 1987

\section{Patients and methods}

Study populations-In Caerphilly and five outlying villages a total sample of middle aged men was selected. The men were chosen by date of birth and when they were seen they were aged 45 to 59 years inclusive. In Speedwell a total sample of men from the age-sex registers of 16 general practitioners working from two health centres in east Bristol was chosen. These men were aged between 45 and 59 inclusive on 1 September 1978, just before the start of the study. In both areas the recruitment phase of the study took between three and four years. Thus the men in the Speedwell study were aged between 45 and 63 years when they were seen.

Survey methods-In Caerphilly a total of 2818 men were eligible for inclusion and were invited to attend one of several local clinics for a cardiovascular examination. In the Bristol population 2550 men were eligible for inclusion in the study and were invited by a letter from their own general prac- 
titioner to attend a single local centre, the Speedwell clinic.

At the clinics in both areas the London School of Hygiene and Tropical Medicine chest pain questionnaire $^{5}$ was administered to all men and a 12 lead electrocardiogram was taken. The electrocardiograms were Minnesota coded and checked ${ }^{5}$ by two experienced observers common to both studies. In both areas a series of other questionnaires was completed and measurements were made. These included details of medical history, smoking habit, occupation (for coding of social class), and family history of ischaemic heart disease. In Caerphilly a record was made of whether the man was currently employed, unemployed, or retired. In both areas height without shoes was measured with a Holtain stadiometer, and the men were weighed on a beam balance. All instruments were checked before each clinic throughout the study.

Definitions of ischaemic heart disease-Angina was defined from the London School of Hygiene and Tropical Medicine chest pain questionnaire in the standard manner as grade 1 (chest pain only on walking uphill or hurrying) and grade 2 (chest pain on walking at an ordinary pace on the level). A past history of possible myocardial infarction was defined from the same questionnaire as a positive answer to the question "Have you ever had a severe pain across the front of your chest lasting for half an hour or more?"

Two categories of electrocardiographic ischaemia were defined: probable electrocardiographic ischaemia was defined by Minnesota codes 1.1 and 1.2 (major and moderate $Q$ waves) and possible electrocardiographic evidence of ischaemia 1.3 (minor $Q$ waves), 4.1 to 4.4 ( $\mathrm{S}-\mathrm{T}$ wave changes), 5.1 to 5.3 ( $\mathrm{T}$ wave inversions), and 7.1 (left bundle branch block). This classification was used by the Whitehall study. ${ }^{2}$

In addition, a combined category of "any ischaemic heart disease" was used. This was defined as the presence of any one or more of the following: angina (grades 1 or 2 ), a past history of possible myocardial infarction, or possible or probable electrocardiographic evidence of ischaemia.

\section{Results}

In Caerphilly 2512 men were examined $(89 \%$ of those eligible). In Speedwell 2348 men were seen ( $92 \%$ of those eligible).

Table 1 shows the ages of the men in the two areas. The mean age of the men in Speedwell was two years more than that of the Caerphilly men. This is because the Speedwell sample was defined by age at a single date (1 September 1978) and the Caerphilly sample was defined by age at date of
Table 1 Age of the men in the two areas

\begin{tabular}{|c|c|c|c|c|c|}
\hline \multirow[b]{2}{*}{ Area } & \multicolumn{4}{|l|}{ Age } & \multirow{2}{*}{ 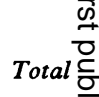 } \\
\hline & $45-49$ & $50-54$ & $55-59$ & $60-63$ & \\
\hline $\begin{array}{l}\text { Caerphilly: } \\
\text { Number of men } \\
\text { Mean age (yr) }\end{array}$ & $\begin{array}{l}828 \\
47 \cdot 4\end{array}$ & $\begin{array}{l}811 \\
52 \cdot 6\end{array}$ & $\begin{array}{l}873 \\
57 \cdot 6\end{array}$ & 二 & 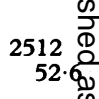 \\
\hline $\begin{array}{l}\text { Speedwell: } \\
\text { Number of men } \\
\text { Mean age (yr) }\end{array}$ & $\begin{array}{c}449 \\
48 \cdot 3\end{array}$ & $\begin{array}{l}727 \\
52.5\end{array}$ & $\begin{array}{c}854 \\
57 \cdot 6\end{array}$ & $\begin{array}{l}318 \\
61 \cdot 1\end{array}$ & $\begin{array}{r}2348 \overrightarrow{0} \\
54 \cdot \dot{ }\end{array}$ \\
\hline
\end{tabular}

examination. In Speedwell only there were men who were aged more than 60 years when seen at the clinic. Also in Speedwell there are fewer men in the youngest age group and those are, on average slightly older than the corresponding men in Cae? rphilly. The 50-59 year age groups are similar in both areas.

Table 2 gives the age specific prevalence of angina. Prevalence of both grade 1 (uphill effor $\$$ only) and grade 2 (on level ground) angina increaseg with age in both areas. The age specific prevalence of both grade 1 and grade 2 angina was very similar i $\bar{b}$ the two areas. In both areas nearly $30 \%$ of men witeo angina had the more severe (grade 2) angina.

Table 3 shows the prevalence of a history of severe chest pain (possible myocardial infarction). Prevas lence increased with age in both areas, but was muc $\bar{B}$ higher in Caerphilly than in Speedwell. Overall, 259 $(10.1 \%)$ men in Caerphilly have had a possible myoo cardial infarction compared with $163(6.9 \%)$ men in Speedwell. After allowing for age, this difference is highly statistically significant $\left(\chi^{2}(1 \mathrm{df})=22 \cdot 7\right.$; $0.001)$. This difference in prevalence was present in every age group.

Table 4 shows the prevalence figures for electron cardiographic evidence of ischaemia. Again preva's lence increased with age and was similar in the two areas for each age group. There was a slight excess of all electrocardiographic evidence of ischaemia i⿱乛龰 Caerphilly at each age, but this area difference is nog statistically significant $\left(\chi^{2}(1 \mathrm{df})=2 \cdot 1 ; 0.05<\mathrm{p} \$\right.$ $0 \cdot 10)$. In both areas almost $4 \%$ of subjects have. major or moderate $Q$ waves (Minnesota Codes 1 . 가 and 1.2).

Men with one or more of the earlier categories of ischaemic heart disease were combined into the cateor gory "any ischaemic heart disease" and table 5 gives the age specific prevalence. One quarter $(25.1 \%)$ of the men in Caerphilly had some evidence of ischaemic heart disease. In Speedwell the overaff prevalence was $23.0 \%$. In fact this underestimate the difference between the two areas because tho Speedwell population is slightly older than that in Caerphilly. If the Speedwell prevalence is adjusted to the Caerphilly age structure by direct standard 
Table 2 Number (\%) of men (and prevalence of angina) by age and angina category

\begin{tabular}{|c|c|c|c|c|c|}
\hline \multirow[b]{2}{*}{ Area } & \multicolumn{4}{|l|}{ Age } & \multirow[b]{2}{*}{ Total } \\
\hline & $45-49$ & $50-54$ & $55-59$ & $60-63$ & \\
\hline $\begin{array}{l}\text { Caerphilly: } \\
\text { Grade } 1 \text { angina } \\
\text { Grade } 2 \text { angina } \\
\text { Any angina } \\
\text { Total number of men }\end{array}$ & $\begin{array}{r}35(4 \cdot 2) \\
10(1 \cdot 2) \\
45(5 \cdot 4) \\
828\end{array}$ & $\begin{array}{l}46(5 \cdot 7) \\
16(2 \cdot 0) \\
62(7 \cdot 6) \\
811\end{array}$ & $\begin{array}{l}60(6 \cdot 9) \\
25(2 \cdot 9) \\
85(9 \cdot 7) \\
873\end{array}$ & E & $\begin{array}{r}141(5 \cdot 6) \\
51(2 \cdot 0) \\
192(7 \cdot 6) \\
2512\end{array}$ \\
\hline $\begin{array}{l}\text { Speedwell: } \\
\text { Grade } 1 \text { angina } \\
\text { Grade } 2 \text { angina } \\
\text { Any angina } \\
\text { Total number of men }\end{array}$ & $\begin{array}{r}16(3 \cdot 6) \\
8(1 \cdot 8) \\
24(5 \cdot 3) \\
449\end{array}$ & $\begin{array}{r}46(6 \cdot 3) \\
12(1 \cdot 7) \\
58(8 \cdot 0) \\
727\end{array}$ & $\begin{array}{l}50(5 \cdot 9) \\
28(3 \cdot 3) \\
78(9 \cdot 1) \\
853^{\star}\end{array}$ & $\begin{array}{l}34(10 \cdot 7) \\
13(4 \cdot 1) \\
47(14 \cdot 8) \\
318\end{array}$ & $\begin{array}{r}146(6 \cdot 2) \\
61(2 \cdot 6) \\
207(8 \cdot 8) \\
2347^{\star}\end{array}$ \\
\hline
\end{tabular}

^Angina category unknown in one man.

isation, then the overall Speedwell prevalence is $20.5 \%$. Table 5 shows that a difference of this magnitude was found in each five year age group.

Table 6 gives the prevalence of each of the possible combinations of the three different categories of ischaemic heart disease for men aged 45 to 59 years. In general, the prevalences were very similar in the two areas. The exception to this was the percentage of men who had a history of severe chest pain (possible myocardial infarction) without either angina or electrocardiographic evidence of ischaemia $(5.6 \%$ in Caerphilly compared with $2 \cdot 6 \%$ in Speedwell). Clearly this is the main reason for the difference in the overall prevalence of any ischaemic heart disease between the areas.

Table 7 compares the prevalence of the various types of ischaemic heart disease in the two areas with that found in three other major British studies.

The Whitehall Study was based on 18403 male civil servants aged 40-64 years working in government departments in London. ${ }^{2}$ The men were examined between 1967 and 1969. Identical questionnaires were used in the present studies but the electrocardiograms, which were Minnesota coded, used the six limb leads only.

The United Kingdom Heart Disease Prevention Project studied 18210 men aged 40-59 years employed in 24 industrial groups working mainly in factories in England and Wales. ${ }^{3}$ The men were examined between 1971 and 1973; questionnaires were those used in the Whitehall Study and a six lead electrocardiogram was Minnesota coded.

The Regional Heart Study was based on a sample of 7735 men aged 40-59 years drawn at random from general practices in 24 British towns representative of a wide range of cardiovascular mortality in England, Wales, and Scotland. ${ }^{4}$ Men were examined during 1978-80; questionnaires were based on those used in the Whitehall Study but the electrocardiogram used was based on three orthogonal leads. This system is suitable for computerised analysis and provides a sensitive measure of the extent of ST and $\mathrm{T}$ wave changes in clinical ischaemia. ${ }^{6}$

Both the Caerphilly and Speedwell studies are based on communities in defined geographical areas-a small town and a suburb respectively. Prevalence figures for Caerphilly and Speedwell are very similar except in the case of severe chest pain (possible myocardial infarction). Figures for the Regional Heart Study are similar to those for Caerphilly with the possible exception of angina, although this may be explained, in part, by the younger age group in the Regional Heart Study. Prevalence figures for the studies among working

Table 3 Number $(\%$ ) of men (and prevalence) by age and past history of possible myocardial infarction

\begin{tabular}{|c|c|c|c|c|c|}
\hline \multirow[b]{2}{*}{ Area } & \multicolumn{4}{|l|}{ Age } & \multirow[b]{2}{*}{ Total } \\
\hline & $45-49$ & $50-54$ & $55-59$ & $60-63$ & \\
\hline $\begin{array}{l}\text { Caerphilly: } \\
\text { Possible myocardial infarction } \\
\text { Total number of men }\end{array}$ & $\begin{array}{l}72(8 \cdot 7) \\
828\end{array}$ & $\begin{array}{l}82(10 \cdot 1) \\
811\end{array}$ & $\begin{array}{l}99(11 \cdot 3) \\
873\end{array}$ & - & $\begin{array}{l}253(10 \cdot 1) \\
2512\end{array}$ \\
\hline $\begin{array}{l}\text { Speedwell: } \\
\text { Possible myocardial infarction } \\
\text { Total number of men }\end{array}$ & $\begin{array}{r}22(4 \cdot 9) \\
449\end{array}$ & $\begin{aligned} 51 & (7 \cdot 0) \\
727 & \end{aligned}$ & $\begin{array}{r}56(6.6) \\
854\end{array}$ & $\begin{array}{l}34(10 \cdot 7) \\
318\end{array}$ & $\begin{array}{r}163(6 \cdot 9) \\
2348\end{array}$ \\
\hline
\end{tabular}


Table 4 Number (\%) of men (and prevalence) by age and electrocardiographic (ECG) evidence of ischaemia

\begin{tabular}{|c|c|c|c|c|c|}
\hline \multirow[b]{2}{*}{ Area } & \multicolumn{4}{|l|}{ Age } & \multirow[b]{2}{*}{ Total } \\
\hline & $45-49$ & $50-54$ & $55-59$ & $60-63$ & \\
\hline $\begin{array}{l}\text { Caerphilly: } \\
\text { Possible ECG ischaemia } \\
\text { Probable ECG ischaemia } \\
\text { All ECG ischaemia } \\
\text { Total number of men }\end{array}$ & $\begin{array}{l}53(6.4) \\
19(2.3) \\
72(8.7) \\
828\end{array}$ & $\begin{array}{l}89(11 \cdot 0) \\
30(3 \cdot 7) \\
119(14 \cdot 7) \\
811\end{array}$ & $\begin{array}{r}113(12.9) \\
49(5.6) \\
162(18.6) \\
873\end{array}$ & $\begin{array}{l}- \\
-\end{array}$ & $\begin{array}{r}255(10 \cdot 2) \\
98(3.9) \\
353(14 \cdot 1) \\
2512\end{array}$ \\
\hline $\begin{array}{l}\text { Speedwell: } \\
\text { Possible ECG ischaemia } \\
\text { Probable ECG ischaemia } \\
\text { All ECG ischaemia } \\
\text { Total number of men }\end{array}$ & $\begin{array}{r}27(6.0) \\
9(2.0) \\
36(8.0) \\
449\end{array}$ & $\begin{array}{l}61(8.4) \\
29(4.0) \\
90(12.4) \\
725^{\star}\end{array}$ & $\begin{array}{r}115(13.5) \\
32(3.7) \\
147(17 \cdot 2) \\
854\end{array}$ & $\begin{array}{r}54(17 \cdot 0) \\
18(5 \cdot 7) \\
72(22 \cdot 6) \\
318\end{array}$ & $\begin{array}{r}257(11.0) \\
88(3.8) \\
345(14.7) \\
2346^{\star}\end{array}$ \\
\hline
\end{tabular}

^Two men had no electrocardiogram.

populations (Whitehall and the United Kingdom Heart Disease Prevention Project) were uniformly lower than those found in the general population studies. This was particularly so for electrocardiographic ischaemia - both possible and probable.

\section{Discussion}

The prevalence of all categories of ischaemic heart disease is very similar in the two areas except for possible myocardial infarction which is much higher in Caerphilly. Because of this the overall prevalence of "any ischaemic heart disease" in Caerphilly is almost $5 \%$ higher than in Speedwell. This difference is in the direction that we might expect given the higher mortality from ischaemic heart disease in the Caerphilly area. The standardised mortality ratio for men for ischaemic heart disease in the Rhymney Valley Health District, which contains Caerphilly, averaged 128 over the period 1980 to 1983; for Frenchay Health District (which contains Speedwell) it averaged 95 over the same period. If the higher mortality was reflected by a higher prevalence of ischaemic heart disease then we would have expected all manifestations of the disease to show this higher prevalence. The prevalence of all electro- $\triangle$ cardiographic evidence of ischaemia is slightly higher in Caerphilly than in Speedwell but, as notedo previously, the difference does not achieve statistical? significance.

The diagnosis of possible myocardial infarction is based on a positive reply to a single question about prolonged, severe chest pain. Of the 253 men in Cae- .0 rphilly who answered positively, 108 (43\%) either did not see a doctor because of the pain or were tolds by the doctor that the origin of the pain was nonischaemic. The corresponding figure in Speedwello was $47(29 \%)$ of 163 men answering positively. This is supported by the fact that in Caerphilly $46 \%$ of the 253 men who had had a prolonged, severe, chest 3 pain answered "No" when asked whether they had? had a heart attack or coronary thrombosis. The cor-O. responding figure in Speedwell was $42 \%$.

Thus the diagnosis of possible myocardia infarction undoubtedly includes false positives:? There is a suggestion from the data above that this 3 false positive rate may be higher in Caerphilly than in Speedwell. In Caerphilly $23 \%$ of men with a past history of myocardial infarction also have angina 0 The corresponding figure in Speedwell is $47 \%$. In Caerphilly, $33 \%$ of men with a past history of myo-o

Table 5 Number ( $\%$ ) of men (and prevalence) by age and presence of any ischaemic heart disease (IHD)

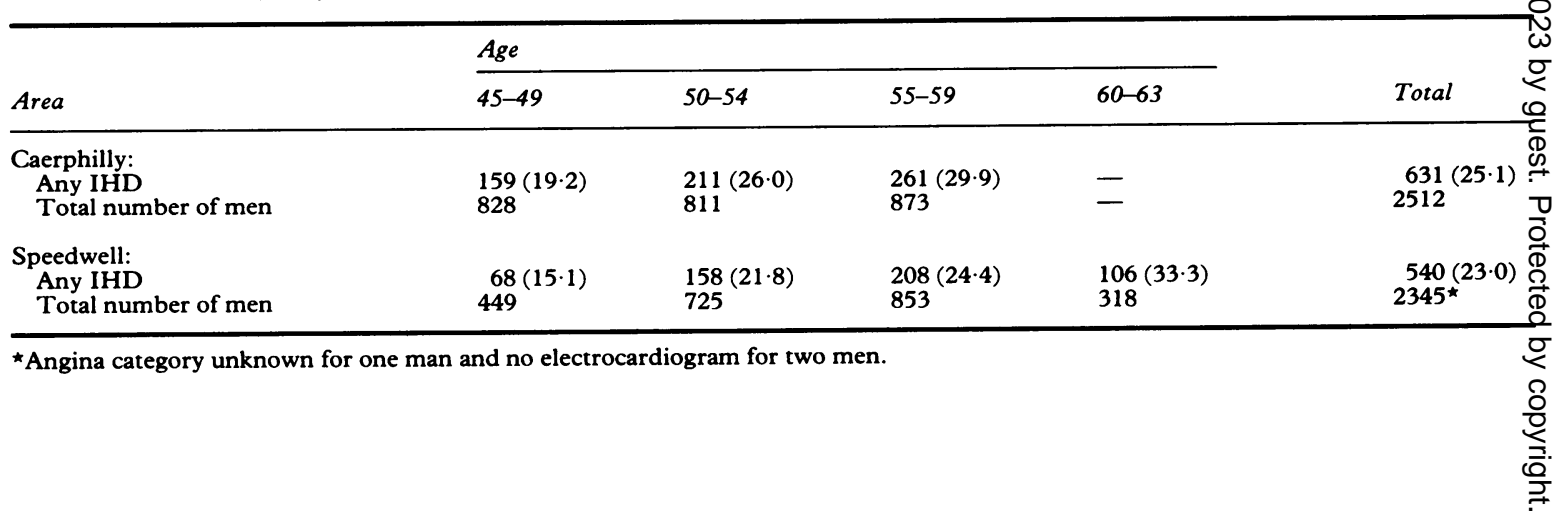


Table 6 Number (\%) of men (and prevalence) with individual categories of ischaemic heart disease (45-59 years only)

\begin{tabular}{|c|c|c|}
\hline Category & Caerphilly & Speedwell \\
\hline $\begin{array}{l}\text { Angina only } \\
\text { Possible myocardial infarct }\end{array}$ & $108(4 \cdot 3)$ & $75(3 \cdot 7)$ \\
\hline $\begin{array}{l}\text { only } \\
\text { ECG ischaemia only } \\
\text { Angina and possible }\end{array}$ & $\begin{array}{ll}141(5 \cdot 6) \\
244(9 \cdot 7)\end{array}$ & $\begin{aligned} 53 & (2 \cdot 6) \\
201 & (9 \cdot 9)\end{aligned}$ \\
\hline $\begin{array}{l}\text { myocardial infarction } \\
\text { Angina and ECG ischaemia }\end{array}$ & $\begin{array}{ll}29 & (1 \cdot 2) \\
26 & (1 \cdot 0)\end{array}$ & $\begin{array}{ll}33 & (1.6) \\
29 & (1.4)\end{array}$ \\
\hline $\begin{array}{l}\text { Possible myocardial } \\
\text { infarction and ECG } \\
\text { ischaemia }\end{array}$ & $54(2 \cdot 1)$ & $20(1.0)$ \\
\hline $\begin{array}{l}\text { Angina, possible myocardial } \\
\text { infarction and ECG }\end{array}$ & & \\
\hline $\begin{array}{l}\text { ischaemia } \\
\text { Any ischaemic heart disease } \\
\text { Total number of men }\end{array}$ & $\begin{array}{r}29(1 \cdot 2) \\
631(25 \cdot 1) \\
2512\end{array}$ & $\begin{array}{l}23(1 \cdot 1) \\
434(21 \cdot 4) \\
2027 \dagger\end{array}$ \\
\hline
\end{tabular}

*All men aged $60-63$ years excluded.

†Angina category unknown for one man and no electrocardiogram for two men.

ECG, electrocardiographic evidence.

cardial infarction had electrocardiographic evidence of ischaemia and $17 \%$ have probable electrocardiographic evidence of ischaemia. The corresponding figures in Speedwell are again higher at $39 \%$ and $20 \%$ respectively. These differences are consistent with the hypothesis of a higher false positive rate for possible myocardial infarction in Caerphilly.

Thus there seem to be very minor differences in the prevalence of ischaemic heart disease between Caerphilly and Speedwell despite a substantial difference in mortality. If it is assumed that the community samples are representative of the health districts for which mortality data are available then clearly a higher incidence of ischaemic heart disease would be expected in the Caerphilly sample given the mortality statistics for the Rhymney Valley. Since the prevalence data are very similar in Caerphilly and Speedwell this implies that the case-fatality rates differ in the two communities. Studies of total incidence in communities show that over $50 \%$ of deaths from ischaemic heart disease occur outside hospital before medical assistance has been summoned. ${ }^{78}$ Clearly many factors operating in or out of hospital may be responsible for different case-fatality rates in the two communities. One possibility is that the effectiveness of community services and hospital treatment may differ between the areas. Another possibility is that some factors present to a greater extent in one area than in the other are more closely associated with fatal cases rather than with surviving cases. In the Regional Heart Study the percentage of heavy smokers in the 24 towns sampled was positively and significantly associated with the standardised mortality ratio for ischaemic heart disease in these towns. ${ }^{9}$ It is possible that smoking habit in particular is more closely associated with mortality from ischaemic heart disease than with morbidity: Caerphilly had about $8 \%$ more current smokers than Speedwell, and Speedwell had 9\% more ex-smokers than Caerphilly.

A comparison of the prevalence of ischaemic heart disease in Caerphilly and Speedwell is facilitated by the common basic protocol of the studies, but comparisons with other British studies (table 7) are hampered by population and methodological differences. Two of the other major studies (Whitehall and United Kingdom Heart Prevention Project) are based on working populations, whereas Caerphilly and Speedwell are based on whole communities which will include both unemployed men and those who have retired early because of ill health. In Caerphilly the men were asked whether they were currently employed or not, and in every age group the prevalence of every category of ischaemic heart disease was higher among men who were not employed. In the youngest men, aged 45-49 years, the prevalence of "any ischaemic heart disease" was $37 \%$, over twice as high as that in employed men. In the two older age groups the prevalence of ischaemic heart disease is about $50 \%$ higher among men not currently employed. If the study had been confined to working men aged 45 to 59 years the overall prevalence of ischaemic heart disease would have been about $21.7 \%$ compared with the $25.1 \%$ actually found in the total population. This factor explains

Table 7 Prevalence (\%) of ischaemic heart disease in middle aged British men

\begin{tabular}{|c|c|c|c|c|c|}
\hline Age range (yr) & $\begin{array}{l}\text { Caerphilly } \\
(45-59)\end{array}$ & $\begin{array}{l}\text { Speedwell } \\
(45-59)\end{array}$ & $\begin{array}{l}\text { Regional Heart } \\
\text { Study }(40-59)\end{array}$ & $\begin{array}{l}\text { Whitehall } \\
\text { Study (40-59) }\end{array}$ & $\begin{array}{l}\text { UK Heart Disease } \\
\text { Prevention } \\
\text { Project (40-59) }\end{array}$ \\
\hline $\begin{array}{l}\text { Angina } \\
\text { Possible myocardial infarction } \\
\text { Possible ECG ischaemia } \\
\text { Probable ECG ischaemia } \\
\text { Any IHD }\end{array}$ & $\begin{array}{c}7 \cdot 6 \\
10 \cdot 1 \\
10 \cdot 2 \\
3 \cdot 9 \\
25 \cdot 1\end{array}$ & $\begin{array}{c}7 \cdot 9 \\
6 \cdot 4 \\
10 \cdot 0 \\
3 \cdot 5 \\
21 \cdot 4\end{array}$ & $\begin{array}{r}4 \cdot 8 \\
9 \cdot 1 \\
11 \cdot 4 \\
3 \cdot 1 \\
23 \cdot 1\end{array}$ & $\begin{array}{l}4 \cdot 3 \\
6 \cdot 5 \\
5 \cdot 0 \\
0 \cdot 5 \star \\
14 \cdot 2\end{array}$ & $\begin{array}{l}3 \cdot 6 \\
6.6 \\
6.9 \\
0.9+ \\
-\end{array}$ \\
\hline
\end{tabular}

^Minnesota codes 1.1 to 1.2 .

+ Minnesota codes 1.1 to 1.3 . 
about half the difference in prevalence figures between the community and working populations shown in table 7. There are also methodological differences between these studies. Although the questionnaire definitions of ischaemic heart disease were all based on those used in the Whitehall Study the prevalence figures for electrocardiographic evidence of ischaemia are not comparable. In the Whitehall Study and the United Kingdom Heart Prevention Project six lead electrocardiograms were used and this would result in a minimum of a $25 \%$ loss of information for overall myocardial ischaemia and perhaps $50 \%$ of $Q$ wave items. ${ }^{10}$ Although there were clinical comparative studies of the three lead orthogonal lead and 12 lead electrocardiogram system in the Regional Heart Study ${ }^{11}$ a different level of sensitivity may apply. Given the different electrocardiographic methods the prevalence of ischaemia in the Regional Heart Study and the present community studies is very similar.

Taken together, these studies, which span a period of 15 years, clearly indicate a persistently high level of both recognised and unrecognised ischaemic heart disease among middle aged British men. Mortality figures ${ }^{12}$ also remain persistently high and further research into this important disease remains a public health priority.

We thank Mr Fred Moore and all members of the survey teams for technical assistance, and Mrs Nan Keen and Ms Ceridwen Rose for the coding of the electrocardiograms.

\section{References}

1 Thom TJ, Epstein FH, Feldman JS, Leaverton PE. Trends in total mortality and mortality from heart

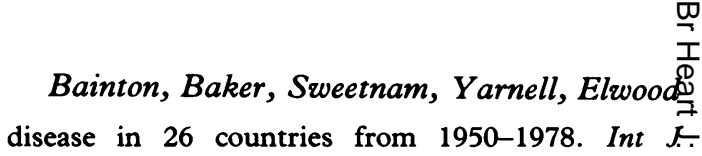
Epidemiol 1986;14:510-20.

2 Rose G, Reid DD, Hamilton PJS, McCartney $\stackrel{P}{\stackrel{5}{+}}$ Keen $\mathrm{H}$, Jarrett $\mathrm{RJ}$. Myocardial ischaemia, ris factors and death from coronary heart disease. Lance $\overline{\bar{O}}$ 1977;i:105-9.

3 WHO European Collaborative Group. Multifactoria品 trial in the prevention of coronary heart disease: 10 Recruitment and critical findings. Eur Heart $f^{s}$ 1980;1:3-80.

4 Shaper AG, Cook DG, Walker M, MacFarlane PW:Prevalence of ischaemic heart disease in middle agedw British men. Br Heart J 1984;51:595-605.

5 Rose GA, Blackburn H. Cardiovascular survey methods 1st ed. Geneva: World Health Organisation, 1968. 엉

6 MacFarlane PW, Melville DI, Horton MR, Bailey JJiv Comparative evaluation of the IBM (12-lead) and tho Royal Infirmary (orthogonal 3-lead) ECG computer programs. Circulation 1981;63:354-9.

7 Pedoe HT, Clayton D, Morris JN, Brigden $\mathrm{W}_{2}^{-}$ McDonald L. Coronary attacks in east London.T Lancet 1975;ii:833-8.

8 Kinlen LJ. Incidence and presentation of myocardia infarction in an English community. $\mathrm{Br}$ Heart 1973;35:616-22.

9 Shaper AG, Pocock SJ, Walker M, Cohen NM $\overrightarrow{0}$ Wale CJ, Thomson AG. British Regional Hearpo Study: cardiovascular risk factors in middle aged men in 24 towns. Br Med J 1981;283:179-86.

10 Evans JG, Tunbridge WMG. Information loss in limblead electrocardiograms compared with twelve leach tracings in a population survey among the elderly Age Ageing 1976;5:56-61.

11 MacFarlane PW, Chen CY, Hulton I, Lorimer AR. A comparison of 3 and 12 lead ECG $T$ wave changes in coronary artery disease. Jpn Heart $J$ 1982;23:465-8.?

12 Office of Population Censuses and Surveys. Mortalityo statistics, England and Wales, 1983. Series DH1, Nò 14. London: HMSO, 1984. 